\title{
A New French Rational Design Method for Airfield
}

\section{Pavements}

\author{
Damien Mounier, Sandrine Fauchet and Michael Broutin \\ Airport Infrastructure Department, French Civil Aviation Technical Center, Bonneuil-sur-Marne 94385, France
}

\begin{abstract}
The aim of this paper is to present the results of a long-term research project consisting in the elaboration of a new rational airfield pavement design procedure applied to flexible pavements. The described methodology is based on the principles and the feedback obtained from the highway pavement design process which has been applied for more than 30 years in France as well as in many other countries. Adaptations to airfield pavements have been made, including features such as accurate traffic description, consideration of lateral wander of aircrafts for instance. The results of these developments have led to a new methodology which enables optimizing pavement designs by considering various input parameters such as the type of pavement section (runway, taxiway or apron), the material properties and the temperature. The complete description of this method is available in the new pavement design manual and it is implemented in the dedicated software Alizé-Airfield Pavement.
\end{abstract}

Key words: Pavement structure, asphalt materials, unbound materials, damage law, frost-thaw.

\section{Introduction}

The previous design procedure for airfield pavements used in France has shown limitations in the past decades. This empirical-based approach does not consider correctly new material performances, temperature effects or new complex landing gear configurations. For flexible pavements, on which this paper is focused, the empirical CBR (California bearing ratio) is used to characterize the bearing capacity of the pavement for the design. These limitations, among others, led the French STAC (Civil Aviation Technical Center) to make new developments to overcome them. These developments [1] are inspired by the rational approach which has been used for roads and highways for more than 30 years. This method is based on the computation of resilient stresses and strains in the pavement structure using a multi-layer linear elastic model. The calculation of a damage parameter in the pavement is made at several

Corresponding author: Damien Mounier, Dipl.-Ing., research fields: pavement design, pavement materials and pavement instrumentation. E-mail: damien.mounier@aviation-civile.gouv.fr. locations, considering fatigue of bound materials and permanent deformations of the soil. The cumulative effect of the loadings applied by the various aircraft of the design traffic mix is taken into account as well as the effect of complex landing gears and wheels interaction. The design thickness of the pavement structure is then determined so as to reach failure at one of the critical level in the pavement after all the aircrafts of the design traffic mix have passed. This corresponds to a damage parameter equal to one.

The development of a specific version of the French software (Alizé-Airfield Pavement) dedicated to airfield pavement design has been done. More information may be found on the STAC's website (www.stac-aviation-civile.gouv.fr).

A comparative study of the previous and the new design methodologies used for French airfield pavement design is proposed in this paper.

Firstly, a description of the principles of the two procedures is presented. They are based on very different developments. Then, a discussion is proposed on the design parameters, and more specifically on the evolutions that are induced due to the new procedure. 
Indeed, progress has been made in the field of pavement research and materials which implies the possibility to use new tools to describe pavement behavior as well as possible.

\section{Previous Design Approach}

The design methodology that was used in France for flexible pavements for several decades is based on the CBR method developed by the US Corps of Engineers [2]. For this type of pavement, several layers of asphaltic materials lie on a granular subgrade and this forms a structure likely to fail where the mechanical performances are the weakest. A failure of the subgrade by excess of vertical stress is assumed for this design procedure.

The procedure takes into account the design traffic over a period of 10 years (20 years for rigid pavements). The former FAA (Federal Aviation Administration) CBR design procedure considered the impact of each aircraft relatively to the design aircraft (aircraft requiring the largest pavement thickness), whereas the French CBR procedure relates the actual number of passes of each aircraft to a fixed traffic volume (10 passes per day for 10 years) with a reduced loading (allowable load). This allowable load is then used for the design.

The type of area to be designed (runway, taxiway and apron) as well as the CBR value of the subgrade is also considered, and the CBR procedure implemented in the French design software (DCA (Dimensionnement des ChausséesAéronautiques) [3]) provides two output parameters for the pavement design: a "total equivalent thickness" and a "minimum equivalent thickness for bound materials". These two parameters, combined with the use of the manual "Bituminous Mixtures and Surface Dressing for Airport Pavements - Guide to the Application of Standards" [4] published by the STAC, enable designing a flexible airfield pavement with the definition of the layers' thickness and material to use. More details about these two different thickness parameters are given in Section 4.1. As for the manual quoted, it is considered as a reference document for flexible airfield pavement designs since it provides guidance for the asphaltic materials selection taking into consideration many aspects (loads of aircrafts, climate, mechanical performances, etc.).

This design procedure has now shown many limitations which led to the development of a new rational design method:

- The CBR parameter, which is meant to represent the bearing capacity of the subgrade, is not a rheological parameter and does not have any actual physical meaning regarding what really happens on site;

- The CBR method is based on the use of "equivalent coefficients" assigned to each material in order to take their stiffness into account. New materials are not characterized very well;

- Variations of temperatures and of speeds of loading are not considered in the procedure. It is yet well known that asphaltic material behavior is very dependent on these two parameters;

- It is quite tricky to extend the design method to new landing gear configurations (e.g., A380, B777 6-W bogies);

- Lateral deviations of aircrafts are considered in the procedure but do not depend on the type of aircraft or the airfield area to design (runway, taxiway or apron);

- An assumption on the mode of failure of the pavement is made and the damage undergone by each of the materials in the pavement structure is not evaluated.

\section{New Developments}

The STAC decided to revise the design procedures of airfield pavements to elaborate a more rational methodology. The development of such a method for flexible airfield pavements was initiated in the 2000s in collaboration with the IFSTTAR (French Institute of Science and Technology for Transport Developments 
and Networks). Indeed, this organization (formerly LCPC (French Central Laboratory of Roads and Bridges)) developed a rational pavement design method for highways that has been used for over 30 years. Therefore, it was chosen to develop the new French airfield pavement design method from the adaptation of the procedure used for highways to airfield pavements [5].

This methodology is based on the theoretical analysis of pavement using the Burmister model [6]. The pavement structure is represented as a multilayered semi-infinite linear elastic model. Each layer is characterized by a modulus value which depends on the temperature and the loading frequency, and a Poisson's ratio with a fixed value of 0.35 (quite representative of the pavement material to a first approximation). The choice of the computing temperature is detailed in Section 4.2. The calculation of strains and stresses in the pavement under a static load enables simulating its behavior under various loading conditions. Further developments may consider a visco-elastic behavior of asphaltic materials.

The next step of the procedure is the use of the calculated strains and stresses to determine the amount of damage undergone by each material of the pavement. A damage parameter is defined at several depths in the pavement, representing the potential modes of failure of the structure (Fig. 1).

In order to simulate the deterioration of the materials, a damage law is implemented. It relates the number of load applications $N$ on top of the pavement structure to the maximum strain $\varepsilon_{\max }$, the material may undergo horizontal tensile strain for HMA (hot mix asphalt), and vertical compressive strain for granular materials. This damage law is expressed as:

$$
N=\left(\frac{\mathrm{K}}{\varepsilon_{\max }}\right)^{\beta}
$$

where, $\beta$ is a positive exponent $(\beta>1)$ and $\mathrm{K}$ is a constant depending on the material.

For a particular strain level, this relation enables determining the number of load applications to failure of the material. This damage law is then combined with the cumulative damage principle (Miner's [7] rule) so as to define the damage parameter $\Delta$ (a material being undamaged for $\Delta D=0$ and completely damaged for $\Delta D=1$ ). More details may be found on the exact definition of this parameter in Ref. [1].

Then, the calculation of the damage parameters is performed using the new airfield pavement design software for a specific pavement structure set by the user (according to his experience) and a particular traffic mix [8]. The layers thicknesses are adjusted until one of the damage parameters reaches the value 1 and the design is considered as valid. The complete procedure is detailed in Ref. [1].

Fig. 2 shows a flow chart of this design procedure with all the necessary input parameters.

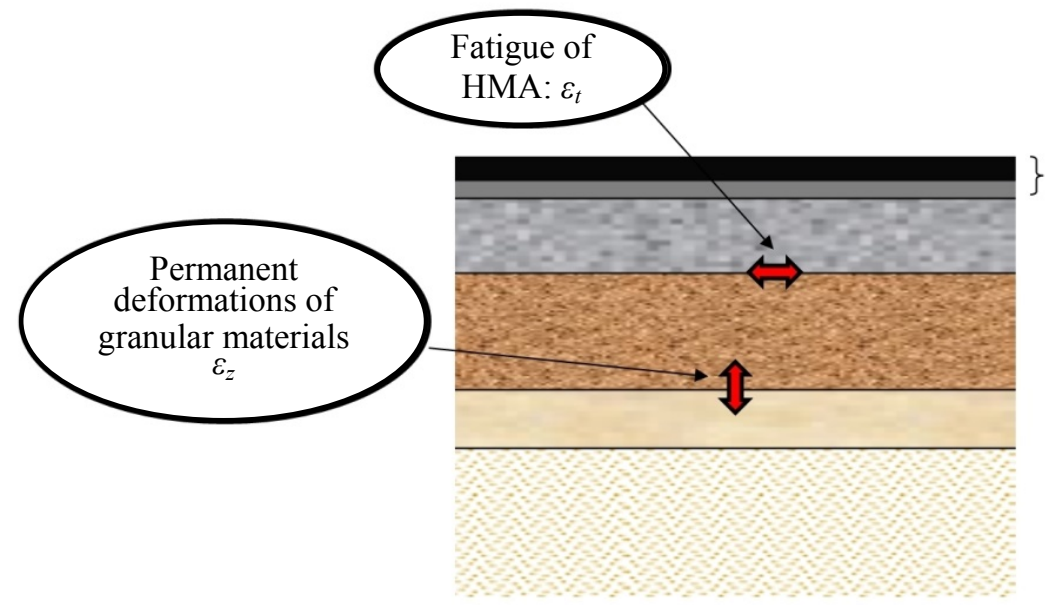

Surface layer(s)

Base layer

Subbase layer

Capping layer

Subgrade

Fig. 1 Potential modes of failure of a flexible pavement. 


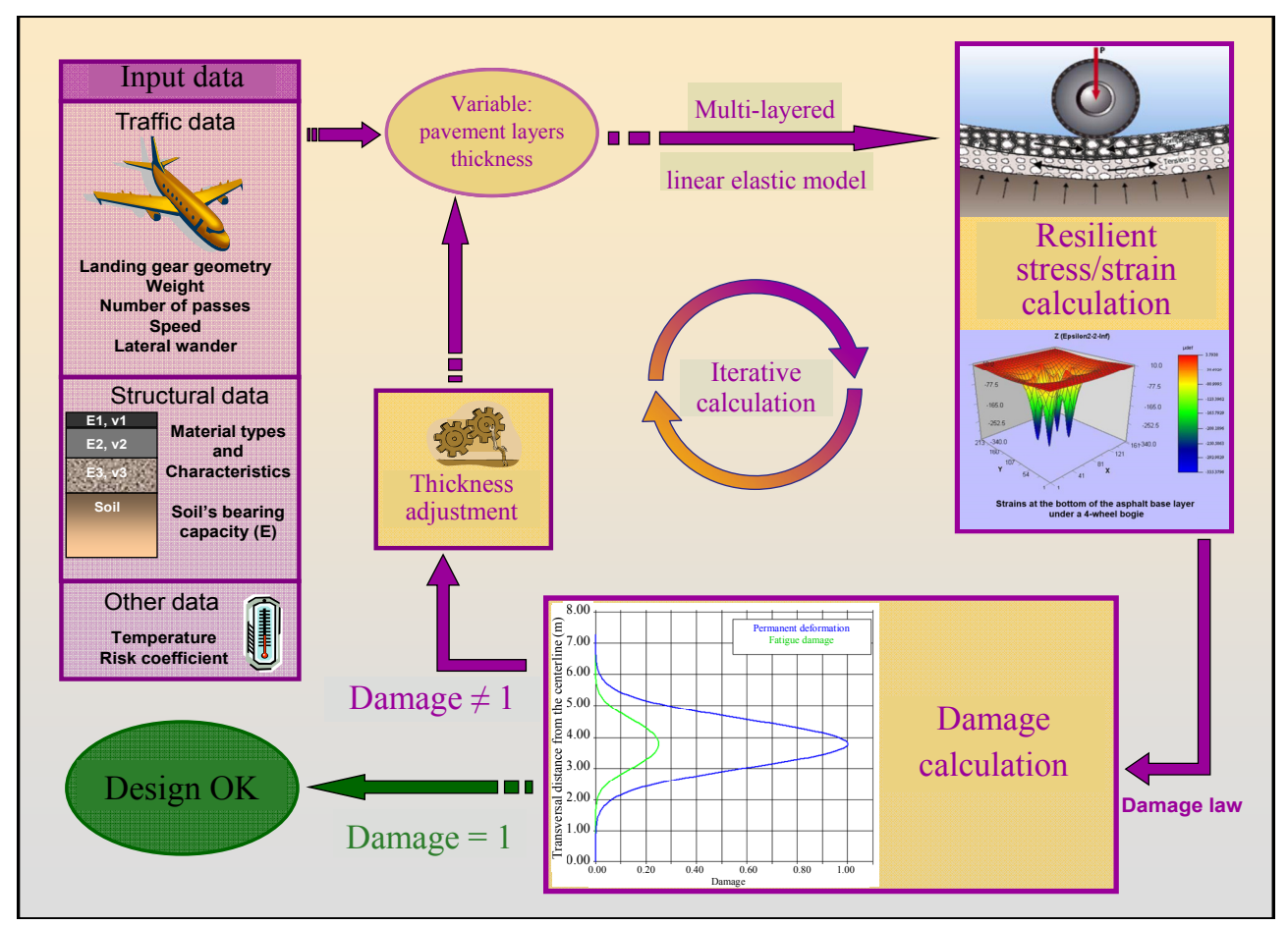

Fig. 2 Flow chart of the new pavement design procedure.

The following sections of this paper provide more explanations about the input parameters used for the former and the new French design methods. In particular, details about the changes induced by the new method on the different parameters are discussed.

\section{Parameters Comparison}

In this section, some of the most important inputs parameters used for pavement design are discussed.

\subsection{Materials}

Materials characteristics are considered quite different in the two design methods. As mentioned in Section 2, the previous design procedure enables determining two parameters: the total equivalent thickness of the pavement and the minimum equivalent thickness of bound materials. This last parameter refers to HMA materials and it is calculated assuming a CBR value of 30 at the top of the subbase. This step was also implemented in the former FAA CBR procedure, but using a CBR value of 20. The equivalent thickness is defined as the sum of the thickness of the pavement layers weighted by "equivalence coefficients" that depend on the type of material. The better the material performances, the higher the equivalence coefficient. Typical equivalence coefficients are shown in Table 1.

The definition of these coefficients is based on field observations, which make the use of new materials quite tricky. Indeed, experimental tests are necessary to determine the value of the coefficient.

This principle is the same as that used in the former FAA CBR procedure, for which "equivalency factors" were introduced.

As for the new design method, the fundamental properties of the materials are implemented: stiffness,

Table 1 Typical equivalence coefficients for new flexible pavement materials.

\begin{tabular}{ll}
\hline Material & Equivalence coefficient \\
\hline Asphaltic concrete, dense coated & 2 \\
macadam & 1.5 \\
Bituminous bound gravel mix & 1.2 \\
Gravel emulsion & 1.5 \\
Gravel treated with wet mix & 1 \\
(cement, slag, light ashes, lime) & 1 \\
Crushed gravel, well graded & 1 \\
Sand treated with wet mix & 1 \\
(cement, slag) & 0.75 \\
Pea gravel & 0.5 \\
Sand &
\end{tabular}


Poisson's ratio, fatigue resistance ( $\varepsilon_{6}$ determined from the fatigue test standard NF EN 12697-24+A1 [9]). The damage law described in Section 3 uses some of these characteristics. Their determination using standard test procedure is therefore sufficient for implementing a new material in the design method.

\subsection{Speed and Temperature}

A particular aspect of airfield pavements is that they are subjected to various types of aircrafts that are significantly different for design purposes. An important parameter associated with this concern is the speed of aircrafts. On aprons, aircrafts are static whereas they move at about $30 \mathrm{kph}$ on taxiways and speeds range from 0 to more than $300 \mathrm{kph}$ on runways.

The effect of speed of aircrafts is considerable on the stiffness of hot mix asphalt as well as the effect of temperature. For these materials, the higher the loading frequency (speed of aircraft) or the lower the temperature, the higher the material stiffness and vice versa. Thus, pavement behavior may be largely dependent on this parameter and that is therefore important to take it into consideration.

The previous design procedure makes the distinction between the different areas on airports (apron, taxiway and runway) (Fig. 3). However, the parameter "speed of aircrafts" is not directly considered. For each area, a multiplicative coefficient (between 0.5 and 1.2) is applied to the weight of aircrafts $(P)$ so as to take effects of speed of aircrafts and temperature in an arbitrary manner, and therefore to adjust the designed structures accordingly. In addition, it has to be noticed that this multiplicative coefficient also takes into account the lateral deviations (wander) of aircrafts. Indeed, for the same number of passes, there are less coverages on runways than on taxiways due to the lateral loads distribution.

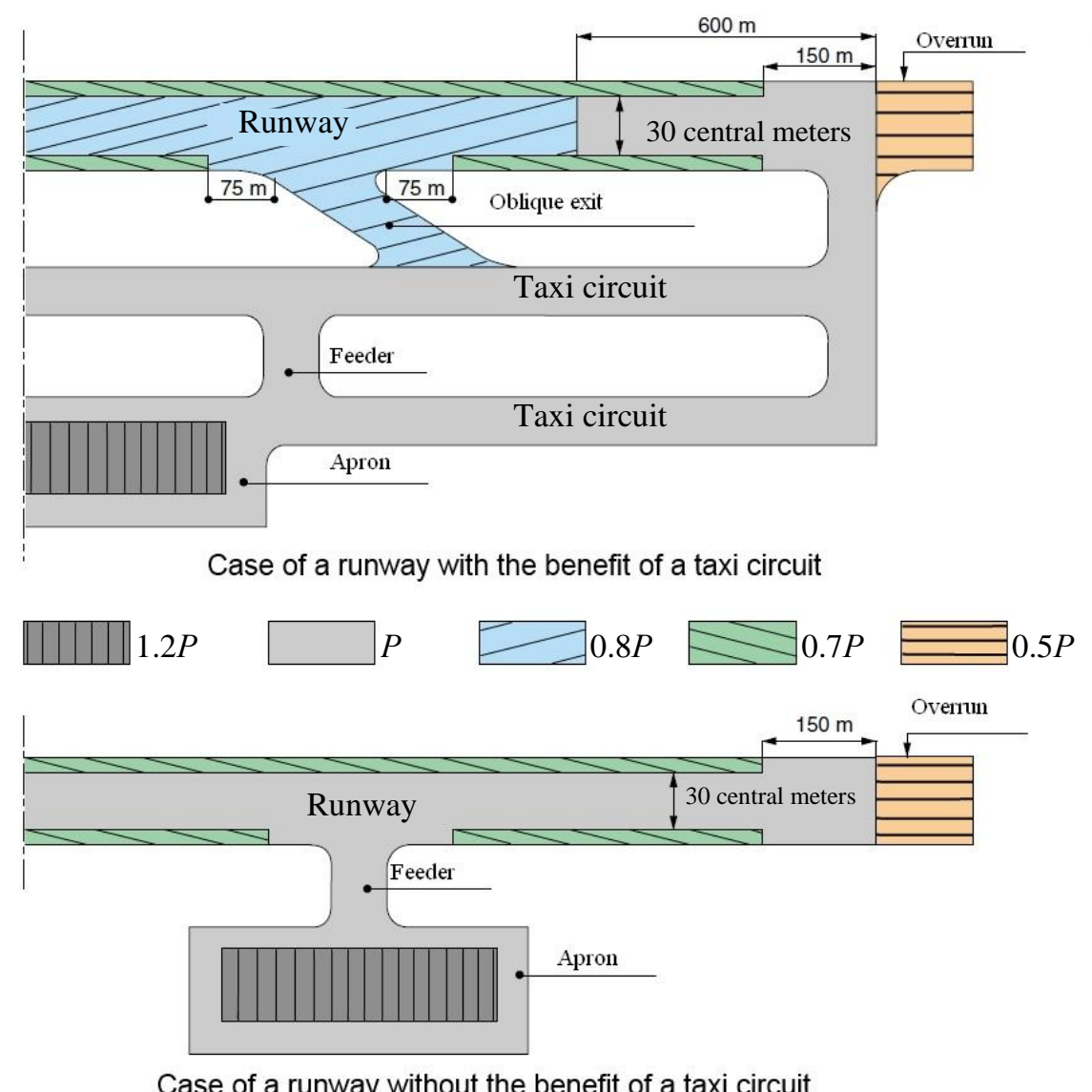

Fig. 3 Distinction of the airfield areas for the current pavement design method. 
This process is improved for the new rational design method since the "real" input values are implemented. In the new software, the user may select the speed of each aircraft as well as a parameter called "equivalent temperature". A more accurate consideration of these two inputs is done. Recommendations on the design speed values to choose are given in the new design guide [1]: $100 \mathrm{kph}$ on runways, $30 \mathrm{kph}$ on taxiways and $10 \mathrm{kph}$ on aprons (a speed equal to zero cannot be used in the model). These speed values are chosen so as to be representative of each section despite the variability that exists particularly for runways. The material stiffness is then adjusted accordingly using temperature and frequency susceptibility charts included in the design software. It has to be noticed that the speed parameter is used for asphalt concrete stiffness calculation, but the calculation of the strains induced by a landing gear is a static calculation.

The equivalent temperature is a parameter calculated from the seasonal temperature histograms at different depths in the pavement. It is a constant temperature chosen for the computation, but it considers the seasonal temperature variations in its definition: the equivalent temperature corresponds to the constant temperature over the design period for which the same damage would be observed as the damage calculated using the seasonal temperature histogram, for a particular aircraft load. Recommendations on this parameter are also provided in the new design guide [1] for typical locations.

\subsection{Lateral Wander}

When trying to simulate the aircraft trajectory on a runway, it is common sense to think that aircrafts are aligned to the runway centerline. In practice, there is a lateral offset from the centerline which is defined as the lateral wander. This phenomenon affects the design calculations on both runway and taxiways since a particular area of the pavement is subjected to less coverages than expected. This results in an extended life of the pavement structure.
As seen in Section 4.2, this physical aspect is considered through the multiplicative coefficient applied on aircraft. In addition, the former design procedure uses another coverage coefficient which is fixed, i.e., it is the same for all the areas of an airfield. It is considered that 36,500 passes correspond to 10,000 actual coverages on a particular area of the pavement: the coverage coefficient is equal to 3.65 .

This approach is empirical and the new design procedure implements a more developed concept included in the damage calculation. This concept is explained in Fig. 4.

It is first assumed that the traffic distribution is modeled as a normal centered distribution characterized by the standard deviation $S_{b a l}$. In Fig. 4, the arrow represents a particular trajectory used by aircrafts away from the centerline. The percentage of traffic passing on this trajectory $\left(P_{j}\right)_{b}$ is defined as the area under the curve contained within a strip of $5 \mathrm{~cm}$ width.

The partial damage associated to aircrafts passing on this trajectory is then calculated using the model described in Section 3 and is represented on the bottom part of Fig. 4. This process is repeated for all the trajectories separated by a distance of $5 \mathrm{~cm}$ for which the damage is not negligible. The overall damage is calculated as the sum of the damages on all trajectories weighted by the percentage of traffic.

This damage calculation based on theoretical developments is summarized with the following expression:

$$
\Delta D_{b a l}\left(y_{j}, z_{k}\right)=\sum_{b=1}^{n_{b}}\left(P_{j}\right)_{b} \times \Delta D\left(y_{j}-\left(y_{j}\right)_{b}, z_{k}\right)(2)
$$

where, $\Delta D_{b a l}$ is the damage considering lateral wander, $y_{j}$ is the transversal position on the runway for which the calculation is made, $z_{k}$ is the depth at which the calculation is made, $n_{b}$ is the number of trajectories considered and $\left(P_{j}\right)_{b}$ is the percentage of traffic passing on trajectory $b$.

In the new design software, the amplitude of wander, 


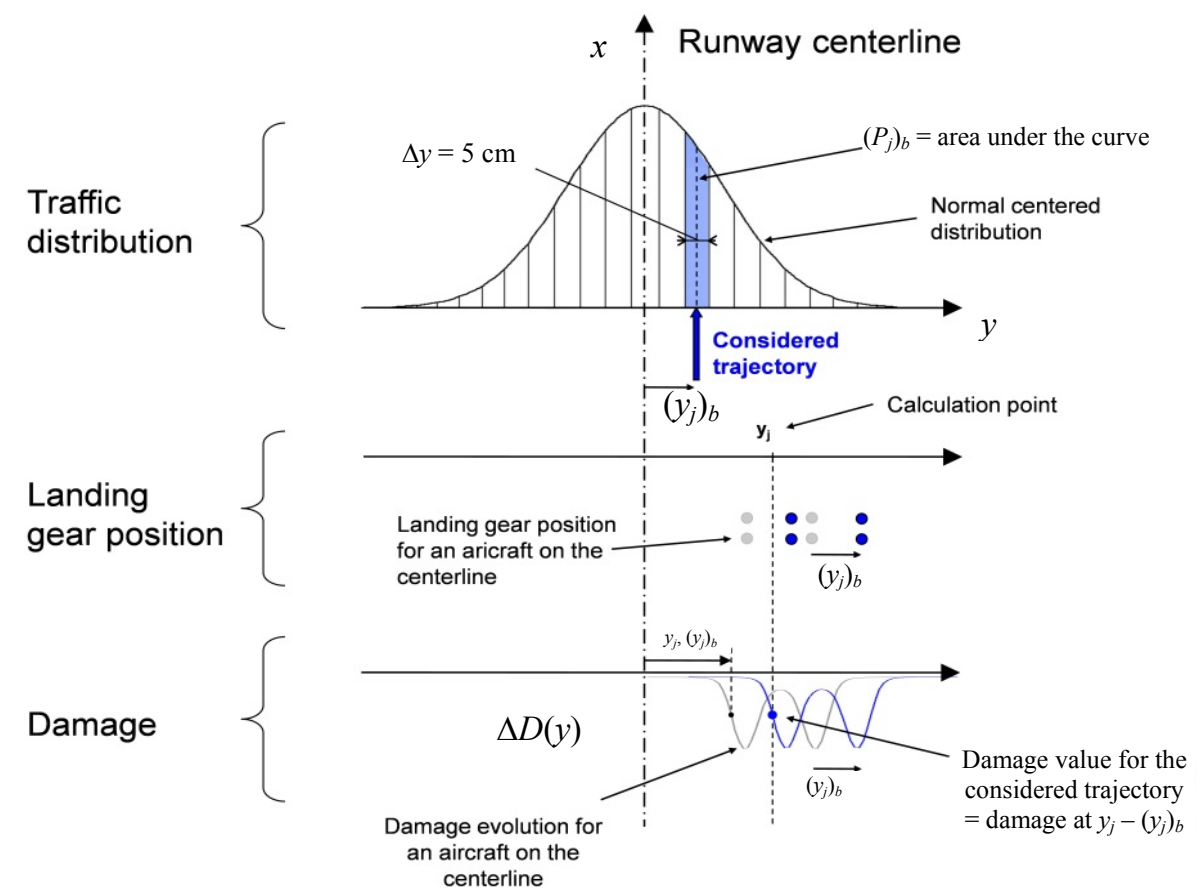

Fig. 4 Lateral wander characterization for the new French design method.

defined as $2 \times S_{b d}$, is an input parameter that has to be set by the user. Based on field surveys, recommendations are given in the design manual [1] for this parameter for the different areas of an airfield: $1.5 \mathrm{~m}$ for runways, $1 \mathrm{~m}$ for taxiways and 0 for aprons.

\subsection{Loadings and Gear Configurations}

There are quite significant differences between the two methods regarding the consideration of landing gears, which may be very different from an aircraft to another.

The previous design method uses a simplification that consists in defining a fictitious individual load (called "equivalent single wheel load", RSE or ESWL), representing the effect on the pavement of a particular main gear. Interaction between two main gears is neglected (which is true for a lot of cases). The Boyd and Foster relation [10] is implemented to determine the equivalent single wheel of each type of main gear, and this is represented as design charts that are then implemented in the DCA software. An example of a design chart is presented in Fig. 5.
Yet, this process gives an approximation of the real loading conditions and is not really easy to implement for new landing gear configurations.

Results of quite recent findings are used in the new design method. The effect of every single wheel of the landing gear is considered, except the nose gear whose effect is often negligible (but that may be considered anyway). The new design software calculates the strains under the effect of the whole landing gear. As an example, Fig. 6 shows a transverse strain signal induced by a main gear in the longitudinal direction (axis of the aircraft).

It has to be noticed that, for the calculation, the considered longitudinal profile under the landing gear is the one for which strains are maximum (usually either directly under the wheels or along the middle axis of the gear).

The "Continuous integration of Miner law" is a theoretical expression that considers the entire strain profile to calculate the damage induced by the whole gear. It is based on the damage law presented in Section 3. A simplified version of this concept considers the peaks ("positive" damage) and the troughs ("negative" 


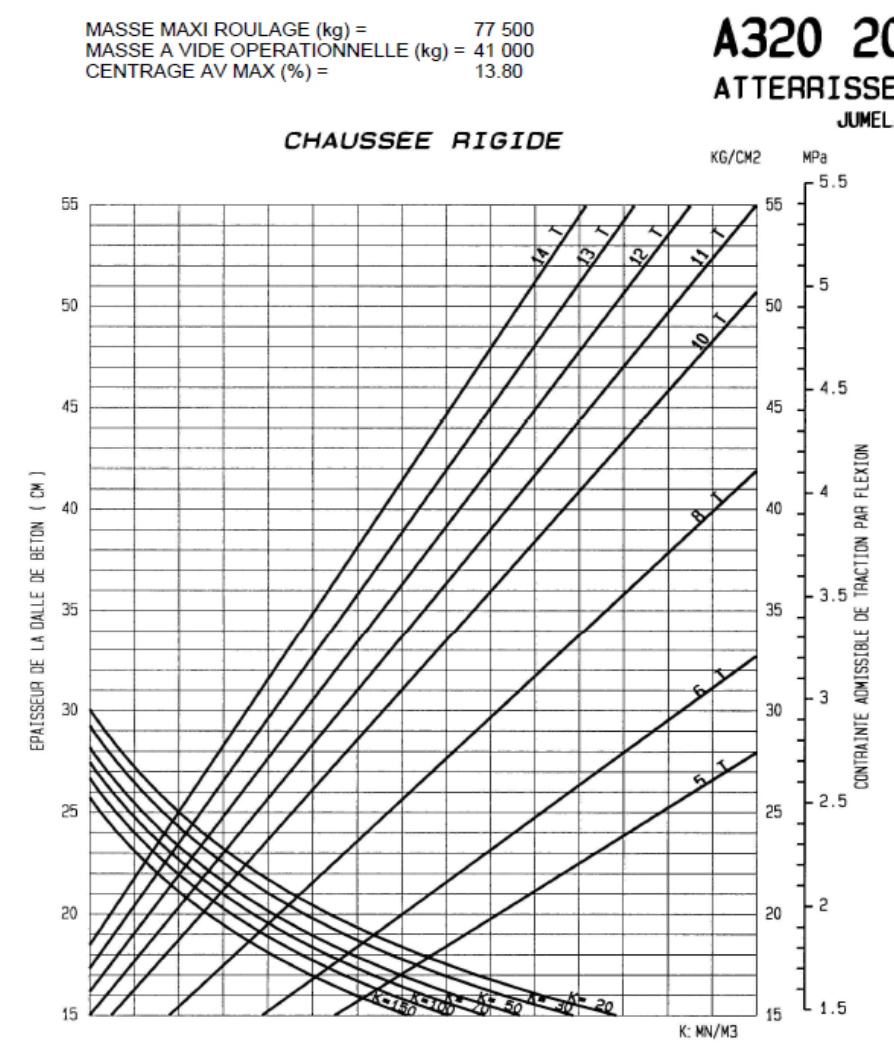

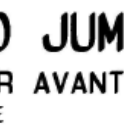

JUMELAGE

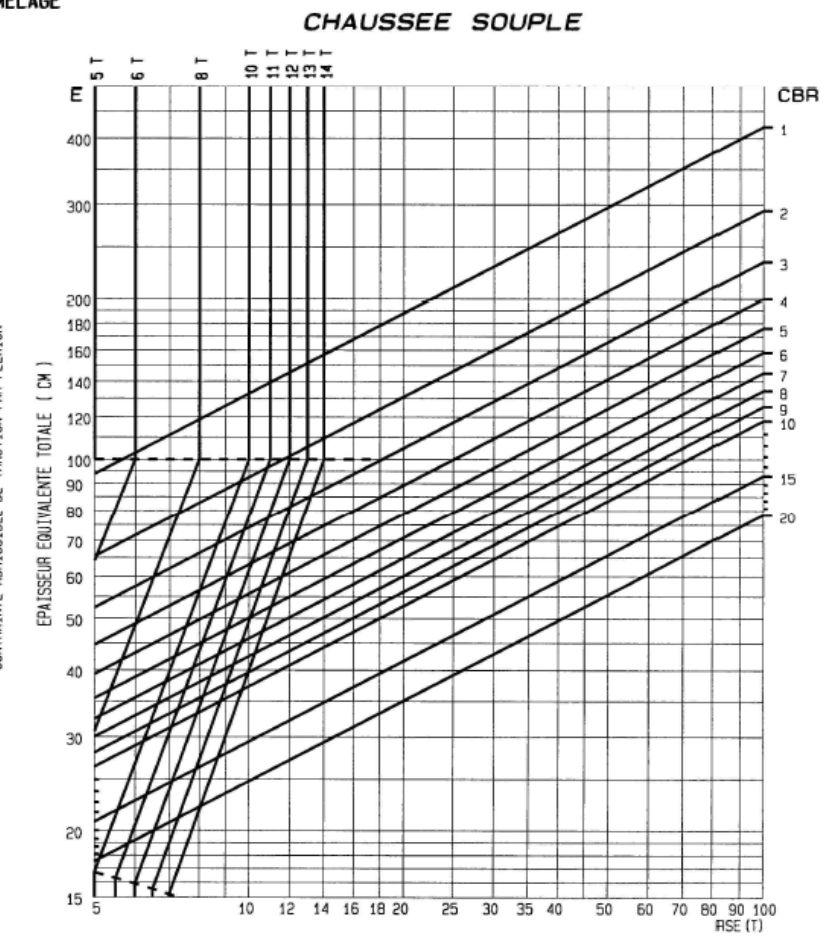

Fig. 5 Example of a design chart for the RSE (ESWL) determination.

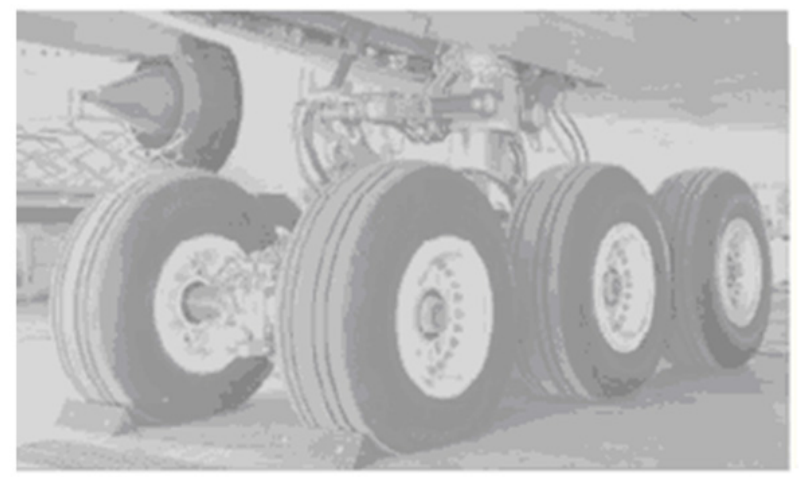

Fig. 6 Transverse strains along a longitudinal profile at the bottom of a hot mix asphalt base layer for a six-wheel bogie.

damage) of the signal (Fig. 6) to calculate the overall damage induced by the landing gear. A "negative" damage may be seen as a sort of healing of the materials. For the example in Fig. 5, the damage would be:

$$
\Delta D_{\text {tridem }}=\frac{1}{\mathrm{~K}^{\beta}}\left(\varepsilon_{t 1}^{\beta}-\varepsilon_{u l 12}^{\beta}+\varepsilon_{t 2}^{\beta}-\varepsilon_{u l 23}^{\beta}+\varepsilon_{t 3}^{\beta}\right)
$$

More details about this principle may be found in

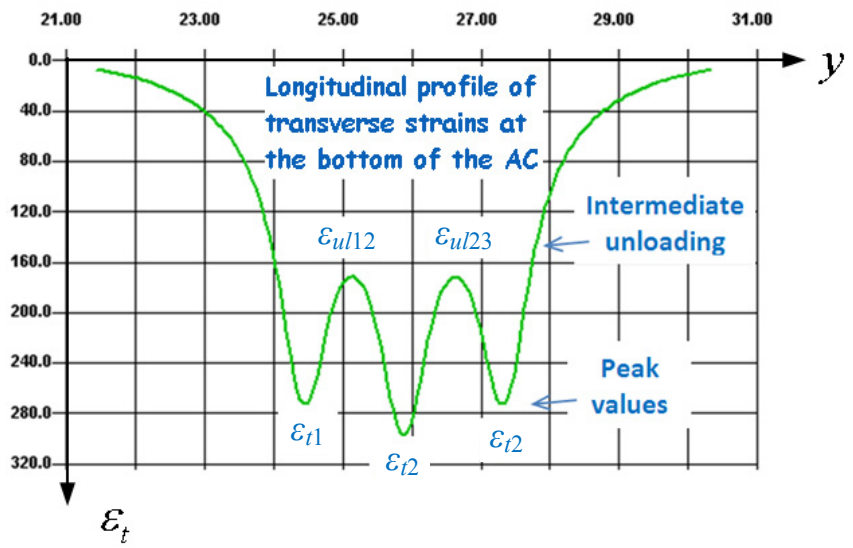

Ref. [1].

\section{Conclusions}

In this paper, brief descriptions of the former and the new airfield pavement design method are proposed. It is shown that the two methods are based on very different principles. Modeling of the pavement structures is contrasting as well as the modes of failure, 
or the description of aircraft loadings. With the new design procedure, all input parameters are detailed and considered in a more realistic manner regarding the behavior of airfield flexible pavements. Furthermore, much more possibilities are given to the user to adapt the design conditions to a standard level of accuracy with the use of recommended parameters or to a more advanced level of accuracy for specific design projects.

In addition, the use of the new design method is more flexible than the current one in the sense that it is easily adaptable to future evolutions (new materials and new aircraft landing gear configurations). Also, since the materials are characterized by fundamental properties, this new method may be used in every country whatever the standard materials.

Finally, future research may be led from this design methodology to be applied to rigid pavements, but also to develop rational ACN (aircraft classification number) and PCN (pavement classification number).

\section{References}

[1] Rational Design Method of Flexible Airfield Pavements-Technical Manual, STAC, France, 2013.

[2] C.R. Foster, R.G. Ahlvin, Development of multiple-wheel CBR design criteria, Journal of the Soil Mechanics and Foundation Division 84 (SM2) (1958) 1-12.
[3] STBA (Airbase Technical Service Department), DCA (airfield pavement design): Airport Structures Design Software Developed by STAC, on the Basis of the Guide, Dimensionnement des Chausses (Pavement Design), 1983. (in French)

[4] Bituminous Mixtures and Surface Dressings for Airport Pavements - Guide to the Application of Standards, STAC, French, 2009.

[5] J.M. Balay, C. Caron, Adaptation of the French rational road design procedure to airfield pavements: The Alizé-Airfield software, in: FAA (Federal Aviation Administration) Technology Transfer Conference, New Jersey, 2010.

[6] D.M. Burmister, The theory of stresses and displacements in layered systems and applications to the design of airport runways, in: Proceedings of Highway Research Board, 1943, pp. 126-148.

[7] M.A. Miner, Cumulative damage in fatigue, Transactions, American Society of Mechanical Engineers 67 (1945) 159-164.

[8] J.M. Balay, C. Caron, P. Lerat, A rational design method for airfield pavements: The French Alizé-Airfield pavement software, European Roads Review 13 RGRA, 2008.

[9] NF EN 12697-24+A1 Standard, Bituminous Mixtures-Test Methods for Hot Mix Asphalt, Part 24: Resistance to fatigue, France, 2007.

[10] W.K. Boyd, C.R. Foster, Design curves for very heavy multiple wheel assemblies, in: Development of CBR Flexible Pavement Design Method for Airfields: A Symposium, Transactions, ASCE 115 (1950) 534-546. 